DOI: $10.1590 / 1089-6891 v 16 i 431444$

MEDICINA VETERINÁRIA

\title{
SENSIBILIDADE DO LAMINOCULTIVO DERMATOBAC@ PARA O DIAGNÓSTICO DA ENDOMETRITE FÚNGICA EM ÉGUAS
}

\section{SENSIBILITY OF MICROCULTIVATION ASSAY DERMATOBAC® FOR FUNGAL ENDOMETRITIS DIAGNOSIS IN MARES}

\author{
Eriky Akio de Oliveira Tongu ${ }^{1}$ \\ Carlos Peleschi Taborda² \\ Shirlei Aparecida Vieira Marques² \\ Gustavo Mendes Gomes ${ }^{3}$ \\ Letícia Patrão de Macedo Gomes ${ }^{3}$ \\ Kleber da Cunha Peixoto Jr. ${ }^{4}$ \\ André Maciel Crespilho ${ }^{3,4^{*}}$
}

\author{
1 Universidade Federal de Uberlândia, UFU, Uberlândia, MG, Brasil. \\ ${ }^{2}$ Instituto de Ciências Biomédicas - ICB II/USP, São Paulo, SP, Brasil. \\ 3Universidade Severino Sombra, USS, Vassouras, RJ, Brasil. \\ ${ }^{4}$ Universidade de Santo Amaro, UNISA, São Paulo, SP, Brasil. \\ *Autor para correspondência - andremacc@yahoo.com.br
}

\section{Resumo}

Dentre os diferentes fatores etiológicos, a endometrite fúngica representa uma causa frequente de infertilidade na égua. Nesse sentido, dois experimentos foram realizados para avaliar a sensibilidade do Dermatobac $\AA$, sistema originalmente desenvolvido para o isolamento de fungos de interesse em Medicina Humana. No Experimento 1, cepas padrão de Candida $(\mathrm{n}=4)$ e Aspergyllus $(\mathrm{n}=1)$ foram semeadas assepticamente e em duplicata no sistema Dermatobac ${ }^{\circledR}$, acompanhando-se o crescimento fúngico a cada 24 horas por 7 dias. Para o Experimento 2, foram selecionadas 34 éguas, submetidas à colheita de material uterino para o plaqueamento em Dermatobac ${ }^{\circledR}$ e realização de esfregaços para pesquisa direta de fungos (Controle). No Experimento 1, foi possível a observação macroscópica de todas as cepas de Candida e Aspergyllus a partir de 24 horas do início do cultivo microbiológico. No Experimento 2, foi constatada a presença de leveduras nas lâminas citológicas de cinco animais $(14,71 \%)$, resultados também confirmados na semeadura em Dermatobac $®$ (sensibilidade de 100\%). Foram observados cinco casos falso-positivos caracterizados pelo crescimento microbiológico em sistema Dermatobac ${ }^{\circledR}$ não confirmados através da citologia endometrial, resultados que determinaram a especificidade de $85 \%$. No entanto, todos os casos falso-positivos foram atribuídos a microrganismos contaminantes que apresentaram morfologia diferenciada e tempo de crescimento superior $(\mathrm{P}<0,05)$ ao apresentado pelos principais agentes etiológicos das endometrites fúngicas equinas. Conclui-se que o sistema Dermatobac ${ }^{\circledR}$ é eficiente para o diagnóstico macroscópico da endometrite fúngica em equinos, gerando informações visuais a partir de 24 horas de cultivo.

Palavras-Chave: Dermatobac $₫$; diagnóstico; éguas; endometrite; fungos.

\footnotetext{
Abstract

Among different etiologic factors, fungal endometritis is a common cause of decreased mare's fertility. Two experiments were conducted to evaluate the sensitivity of Dermatobac $\AA$, a microculture system
} 
originally developed for the isolation of fungi that concerns Human Medicine. In Experiment 1, standard (ATCC) strains of Candida $(\mathrm{n}=4)$ and Aspergyllus $(\mathrm{n}=1)$ were grown and visually analyzed daily for 7 days. For Experiment 2, 34 mares were selected and subjected to material harvesting for completion of uterine cytology as well as seeding with Dermatobac ${ }^{\circledR}$. After $24 \mathrm{~h}$ of cultivation, the macroscopic observation of all Candida and Aspergyllus strains (Experiment 1) was possible. In Experiment 2, five animals showed presence of yeast on cytologic slides $(14.71 \%)$, results also confirmed sowing in Dermatobac ${ }^{\circledR}$ system (100\% sensitivity). Five false positive cases were observed, characterized

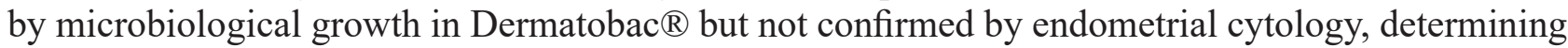
specificity of $85 \%$. However, the results did not compromise the efficiency of Dermatobac ${ }^{\circledR}$ system given all contaminants presented differentiated morphology and higher growing time $(\mathrm{P}<0.05)$ when compared to the major etiological agents of equine fungal endometritis. The Dermatobac $\mathbb{}$ system proved to be efficient for the macroscopic diagnosis of fungal endometritis in horses, showing conclusive information only after 24 hours of culture.

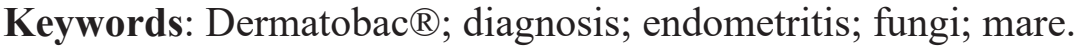

Recebido em: 13 agosto 2014

Aceito em: 18 junho 2015

\section{Introdução}

A endometrite corresponde a um processo inflamatório que envolve a camada superficial do útero chamada endométrio e representa uma das principais causas de infertilidade na égua ${ }^{(1)}$. A patologia pode ser classificada em endometrite infecciosa, endometrite persistente induzida pelo coito e endometrite crônica também denominada endometriose ${ }^{(2)}$.

A etiologia e fatores predisponentes da endometrite na égua envolvem defeitos anatômicos na conformação vulvar, histórico de partos distócicos, retenção de placenta, infecções iatrogênicas e falhas nos mecanismos fisiológicos de clearence uterino após a monta natural ou inseminação $\operatorname{artificial}^{(3,4)}$. De acordo com Dascanio ${ }^{(5)}$, a endometrite fúngica representa uma causa frequente de infertilidade em equinos, sendo que cerca de 5\% das éguas com diagnóstico de endometrite infecciosa apresentam infecções causadas por fungos.

Os fungos são microrganismos oportunistas apontados como agentes etiológicos das endometrites em equinos ${ }^{(6)}$. Alguns fatores de risco como imunossupressão, manipulação excessiva durante a realização de biotécnicas reprodutivas, abuso no uso de antibióticos, conformação perineal alterada, idade e pluriparidade podem aumentar a incidência das endometrites fúngicas ${ }^{(7)}$. As espécies de fungos mais comumente isoladas dos quadros de endometrite pertencem ao gênero Candida spp $e$ Aspergillus spp, espécies leveduriformes que podem ser identificadas através de exame microscópico direto realizado a partir de citologia esfoliativa endometrial ${ }^{(8,9)}$.

O diagnóstico da endometrite pode ser realizado por meio de exame ginecológico, palpação retal, ultrassonografia transretal, citologia e cultura de conteúdo uterino ${ }^{(10,11)}$. Entretanto, a dificuldade de implantação de um método diagnóstico confiável tem sido um grande desafio, causando diagnósticos falso-positivos ou falso-negativos, comprometendo a avaliação clínica do animal e a conduta terapêutica do médico veterinário ${ }^{(12,13)}$.

A citologia uterina tem sido descrita como um método rápido e confiável para se obter informações sobre o estado de inflamação endometrial ${ }^{(14)}$, sendo apontado como o método mais sensível e precoce para o diagnóstico de endometrites causadas por fungos e bactérias ${ }^{(15,16)}$. Entretanto, a falta de familiaridade com a técnica e a dificuldade apresentada por muitos profissionais durante a avaliação dos esfregaços pode gerar avaliações pouco confiáveis e erros no diagnóstico ${ }^{(16,17)}$.

Estudos anteriores demonstraram que a utilização de um único método muitas vezes é insuficiente para o diagnóstico preciso de infecções fúngicas ${ }^{(5,18)}$. Dessa forma, a combinação do exame citológico e cultura microbiológica representa uma ferramenta de grande utilidade para a identificação dos quadros de endometrite fúngica, conferindo maior sensibilidade diagnóstica ${ }^{(13,15)}$. No entanto, como muitos 
centros equestres encontram-se distantes das grandes cidades, a logística para envio de amostras biológicas para cultura e isolamento laboratorial pode representar um importante fator limitante ${ }^{(13,18)}$. Recentemente, foi lançado no Brasil um kit comercial para diagnóstico de fungos de interesse em Medicina Humana denominando Dermatobac ${ }^{\circledR}$ (Probac, São Paulo, Brasil). Em Medicina Veterinária, esse sistema de cultivo já se mostrou efetivo em estudos anteriores para o diagnóstico rápido e preciso de dermatofitoses em felinos ${ }^{(19)}$ e caninos $^{(20)}$. Por apresentar baixo custo, facilidade de aquisição e dispensar uma estrutura laboratorial complexa para a identificação fúngica, o sistema apresenta grande potencial para aplicação em Medicina Veterinária.

Nesse sentido, objetivou-se avaliar a sensibilidade do sistema Dermatobac ${ }^{\circledR}$ para o diagnóstico das infecções uterinas de origem micótica, assim como avaliar a prevalência da endometrite fúngica no grupo de risco para a doença, composto por éguas idosas, pluríparas e/ou com histórico reprodutivo de infertilidade.

\section{Material e Métodos}

O trabalho foi aprovado pelo Comitê de Ética em Pesquisa no Uso de Animais (CEUA- UNISA, São Paulo, Brasil; parecer $n^{\circ}$. 33/2013), sendo iniciado no ano de 2013. Para o estudo, foi utilizado o sistema de laminocultivo Dermatobac ${ }^{\circledR}$ (Probac do Brasil Ltda, São Paulo, Brasil), que possui três placas de microcultivo compostas por ágar Saboraud glicose, Biggy e DTM (Figura 1), que permitem não apenas a identificação de fungos filamentosos dos gêneros Microsporum, Epidermophyton e Trichophyton, como também de muitas espécies de leveduras. De acordo com informações fornecidas pelo fabricante, embora o crescimento de leveduras possa ocorrer em qualquer uma das três placas, o ágar Biggy apresenta a maior seletividade, sendo recomendado para o isolamento, sobretudo de leveduras do gênero Candida.

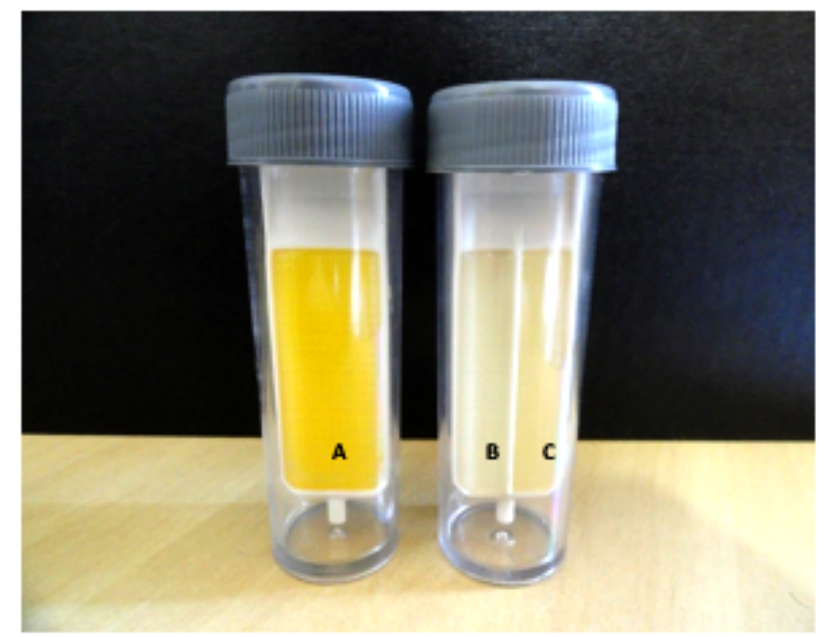

Figura 1: Laminocultivo Dermatobac® (Probac do Brasil Ltda, São Paulo, Brasil) apresentando três placas de microcultivo compostas por ágar DTM (A), ágar Biggy (B) e ágar Saboraud glicose (C).

Foram realizados dois experimentos. No Experimento 1, avaliou-se a sensibilidade do microcultivo, utilizando-se cepas fúngicas padrão de Candida albicans (ATCC 10231), C. glabrata (ATCC 90030), C. tropicalis (ATCC 13803), C. krusei (ATCC 6258) e Aspergyllus spp. (ATCC 16404), obtidas junto à micoteca do Instituto de Ciências Biomédicas da Universidade de São Paulo (São Paulo, SP, Brasil). Para evitar contaminação cruzada, todas as amostras foram manipuladas com alça de platina estéril no interior de capela microbiológica e com o auxílio de bico de Bunsen para a semeadura no sistema 
Dermatobac $\AA$. Além dos principais agentes etiológicos das endometrites fúngicas em equinos, foram também semeadas culturas dos fungos contaminantes ambientais Penicillium spp (ATCC 46767) e Cladosporium spp (ATCC 32720). Todos os inóculos permaneceram à temperatura ambiente e foram acompanhados visualmente a cada 24 horas por sete dias. Além da avaliação morfológica dos diferentes gêneros fúngicos, neste experimento foi testada a hipótese de que os fungos potencialmente patogênicos podem apresentar velocidade de crescimento diferente dos fungos contaminantes ambientais, favorecendo a identificação através do sistema Dermatobac $®$.

No Experimento 2, avaliou-se a prevalência da endometrite fúngica no grupo de risco para a doença. Para tanto foram selecionadas 34 éguas adultas da raça Mangalarga Marchador, pluríparas, pertencentes a duas propriedades rurais situadas na cidade de Vassouras, RJ, Brasil, com peso médio de $400 \mathrm{~kg}$ e submetidas ao mesmo regime nutricional à base de capim Napier picado, $4 \mathrm{~kg}$ de ração comercial, contendo $12 \%$ de proteína, ao dia e livre acesso à água.

Para a seleção das éguas, foram utilizados três critérios de inclusão: idade superior a 12 anos; presença de defeitos na conformação anatômica da genitália externa (horizontalização de vulva); histórico de infertilidade após inseminação artificial ou coberturas consecutivas. Dessa forma, apenas as éguas que apresentaram no mínimo dois dos três critérios considerados como fatores de risco para a endometrite ${ }^{(8,21)}$ foram inclusas no experimento. Além disso, todos os animais encontravam-se na fase de diestro durante a colheita de material endometrial.

Após a cauda ser enfaixada e realizada a antissepsia da vulva e períneo com sabão neutro, cada égua foi submetida à colheita asséptica de material endometrial por meio de aparelho de citologia de aço inoxidável e escova citológica estéril, que permaneceu em contato com a parede uterina por 15 segundos realizando-se movimentos de rotação, de acordo com Aguilar et al. ${ }^{(11)}$. O material endometrial foi repicado em frascos contendo solução salina estéril e plaqueado através de movimentos de "ziguezague" e sem sobreposição nas três placas de microcultivo que compõem o sistema Dermatobac®. Adicionalmente, para o exame citológico direto (Controle), foram utilizadas as mesmas amostras endometriais para confecção de esfregaços em lâminas foscas de vidro, evitando-se a sobreposição de material durante o processamento citológico. Todas as lâminas foram fixadas em álcool metílico para posterior coloração com Panótico rápido e avaliação em microscopia de luz sob aumento de $1000 \mathrm{X}$ em objetiva de imersão ${ }^{(22)}$.

Após a semeadura asséptica com auxílio de bico de Bunsen, os sistemas Dermatobac $₫$ permaneceram sob temperatura ambiente, sendo avaliados visualmente a cada 24 horas durante três semanas. Adicionalmente, as amostras cultivadas que exibiram crescimento no Dermatobac ${ }^{\circledR}$ foram submetidas a novo cultivo microbiológico comprobatório em ágar Sabouraud Dextrose com corante Lactofenol Azul, além da prova do tubo germinativo ${ }^{(23)}$ para a identificação em condições laboratoriais das cepas fúngicas isoladas a partir das amostras de campo.

Para comparação da velocidade média de crescimento de cada uma das cepas fúngicas semeadas no Experimento 1, foi utilizado modelo linear geral (GLM) de análise de variância (SAS, Cary, USA). Para análise comparativa de sensibilidade da cultura em Dermatobac ${ }^{\circledR}$ frente ao exame citológico direto, foi utilizado o Índice Kappa de concordância para o intervalo de confiança de $95 \%$ através do software computacional BioEstat versão 4.0 (Belém, Pará, Brasil).

A sensibilidade e especificidade do sistema de microcultivo foram testadas por meio das seguintes equações: Sensibilidade $(\%)=\mathrm{VP} /(\mathrm{VP}+\mathrm{FN}) \times 100$; Especificidade $(\%)=\mathrm{VN} /(\mathrm{VN}+\mathrm{FP}) \times 100$, em que VP: verdadeiro positivo; FN: falso negativo; VN: verdadeiro negativo; FP: falso positivo. Diferenças foram consideradas quando $\mathrm{P}<0,05$.

\section{Resultados e Discussão}

As infecções endometriais de origem fúngica representam um verdadeiro desafio terapêutico, já que em muitos casos os animais manifestam-se refratários ao tratamento antifúngico, apresentando infertilidade por períodos prolongados de tempo ${ }^{(8)}$. Por essa razão, o diagnóstico rápido e preciso 
representa a melhor alternativa para correta abordagem da doença, diminuindo o impacto econômico negativo sobre a produção de equinos.

No Experimento 1, após 24 horas de cultivo microbiológico, foi possível observar de maneira macroscópica todas as cepas de Candida spp (colônias cremosas de cor marrom, Figura 2A) que cresceram em pelo menos um dos três laminocultivos do sistema Dermatobac ${ }^{\circledR}$ (Tabela 1).

Tais resultados assemelham-se aos reportados por Dumitru et al. ${ }^{(24)}$, que observaram que, mesmo em condições anaeróbicas a Candida albicans possui tempo de duplicação de apenas 20 horas. De acordo com os mesmos autores, em condições de aerobiose, o tempo para duplicação em meios próprios para espécie é de apenas duas horas, justificando a rapidez na obtenção dos resultados de cultivo. De acordo com Alterthum e Trabulsi ${ }^{(25)}$, além da alta taxa de crescimento, a aparência macroscópica das colônias permite uma identificação conclusiva das cepas de Candida spp, garantindo segurança para a interpretação dos resultados do cultivo.

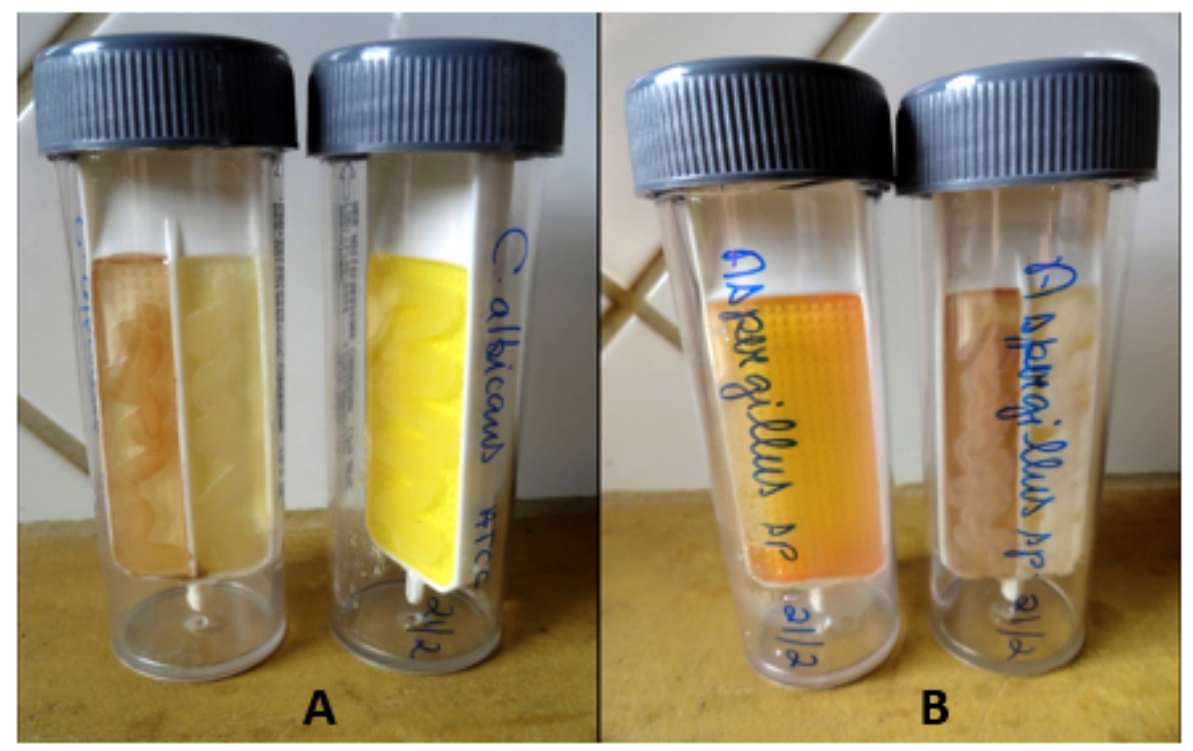

Figura 2: Amostras padrão (ATCC 10231 e 16404) de Candida albicans (A) e Aspergyllus spp (B) observadas a partir de 24 horas de cultivo no sistema Dermatobacß). Além do padrão característico de cada colônia fúngica, o crescimento das cepas de Candida e Aspergyllus foi acompanhado por alterações na coloração, respectivamente, do ágar Biggy (de branco à marrom) e DTM (de amarelo à avermelhado).

Todas as cepas ATCC de Candida cresceram primeiramente no ágar Biggy (Tabela 1), cultivo especialmente desenvolvido para isolamento dessa espécie de fungo ${ }^{(19)}$. O crescimento também foi acompanhado pela alteração da coloração do cultivo, passando de branco a marrom em virtude da redução do sulfito de bismuto presente no ágar Biggy, característica metabólica que auxilia na identificação das diferentes espécies de Candida $^{(28)}$. De acordo com Iikit et al. ${ }^{(26)}$, os sais de bismuto atuam como um agente inibidor, suprimindo o crescimento bacteriano e indiretamente estimulando o crescimento das colônias de Candida. Em ágar Saburond Glicose, as cepas de Candida spp apresentaram aspecto cremoso e liso de cor creme, características compatíveis com o padrão de crescimento esperado nesse tipo de meio ${ }^{(27)}$. Já no ágar DTM, por ser especifico para identificação de dermatófitos, foi observada a menor taxa de crescimento das colônias de Candida spp, não havendo alterações perceptíveis de coloração do meio ao longo do período de incubação 
Tabela 1: Observação macroscópica de diferentes cepas ATCC de Candida, Aspergyllus spp, Cladosporium spp e Penicillium spp durante as primeiras 24 horas de cultivo em sistema Dermatobac®), em função do tipo de ágar presente nas placas de microcultivo

\begin{tabular}{cccc}
\hline Gênero & Agar DTM & Agar Sabouraud & Agar Biggy \\
\hline Candida albicans & $\mathrm{X}$ & $\mathrm{X}$ & $\mathrm{X}$ \\
Candida krusei & $\mathrm{SC}$ & $\mathrm{X}$ & $\mathrm{X}$ \\
Candida glabrata & $\mathrm{SC}$ & $\mathrm{X}$ & $\mathrm{X}$ \\
Candida tropicalis & $\mathrm{SC}$ & $\mathrm{SC}$ & $\mathrm{X}$ \\
Aspergillus spp & $\mathrm{X}$ & $\mathrm{X}$ & $\mathrm{X}$ \\
Cladosporium $s p p$ & $\mathrm{SC}$ & $\mathrm{SC}$ & $\mathrm{SC}$ \\
Penicillium $s p p$ & $\mathrm{SC}$ & $\mathrm{SC}$ & $\mathrm{SC}$ \\
\hline
\end{tabular}

Em hue " $\mathrm{X}$ ": Observação macroscópica de crescimento da colônia fúngica; "SC": sem crescimento evidenciável ou alteração de coloração do meio de cultivo.

O padrão de crescimento do fungo Aspergyllus spp foi semelhante ao apresentado pelas cepas de Candida spp, permitindo o diagnóstico macroscópico a partir de 24 horas de cultivo em sistema Dermatobac ${ }$. Macroscopicamente, o crescimento das cepas ATCC de Aspergyllus spp foi caracterizado por colônias filamentosas de cor branca a creme (Figura 2B) e pela formação de esporos, características comuns dos fungos dessa espécie ${ }^{(23)}$. O crescimento das cepas de Aspergyllus spp também foi acompanhado pela mudança da coloração do meio de cultivo DTM (de amarelo tornou-se avermelhado), alteração macroscópica evidenciada a partir de 48 horas de incubação (Figura 2B). Nos meios Biggy e ágar Saburond Glicose também foi evidenciado o crescimento de colônias filamentosas, algodonosas com coloração variando do branco ao verde claro.

Já as cepas de Penicillium spp e Cladosporium spp, ambos fungos contaminantes ambientais, precisaram em média de 80 horas para exibirem crescimento $(\mathrm{P}<0,05)$ caracterizado pela observação macroscópica de colônias da cor bege clara e verde escuro, respectivamente (Figuras 3A e 3B).

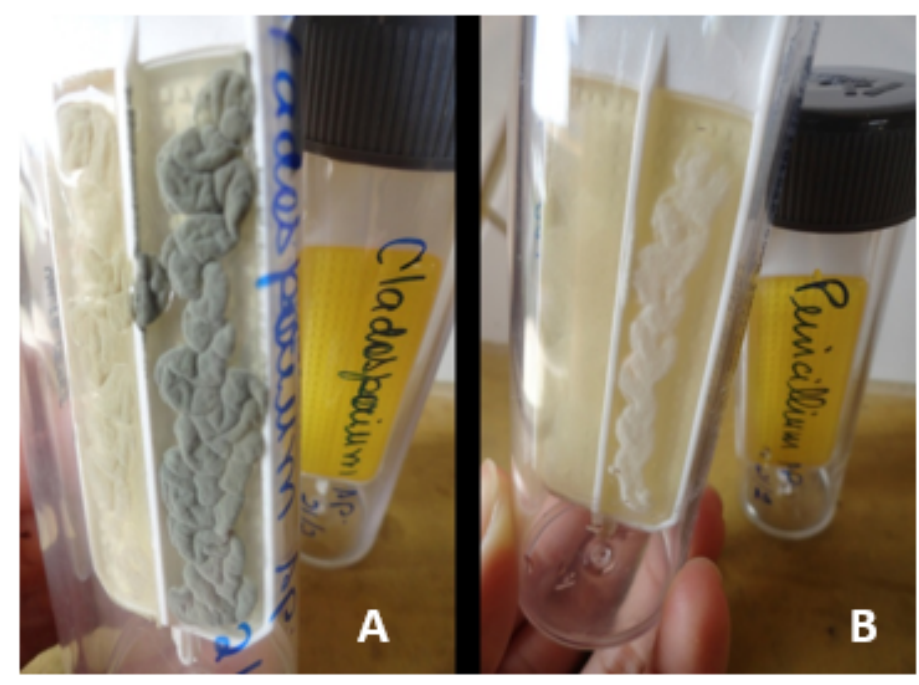

Figura 3: Cepas padrão (ATCC 32720 e 46767), respectivamente, dos fungos contaminantes ambientais Cladosporium spp e Penicillium spp. Além das características macroscópicas quando comparados às cepas de Candida e Aspergyllus, a observação desses fungos no sistema Dermatobac@ só foi possivel a partir de 80 horas de cultivo. 
$\mathrm{O}$ crescimento dos fungos contaminantes ocorreu preferencialmente nas placas de meio Biggy e ágar Saboraud glicose, sendo evidenciado crescimento no meio DTM somente após 200 horas de cultivo. Dessa forma, o tempo de crescimento e características morfológicas das colônias permitiram o diagnóstico diferencial dos fungos potencialmente patogênicos relacionados à endometrite equina dos fungos contaminantes ambientais.

No Experimento 2, foi observada a prevalência de 14,71\% (5 casos em 34 éguas pesquisadas) para os quadros de endometrite fúngica em equinos, resultados superiores aos reportados em estudos anteriores que indicaram valores próximos a $5 \%{ }^{(6)}$. Tais resultados se justificam pelos critérios de inclusão adotados no presente estudo, utilizando-se apenas éguas com histórico de baixa fertilidade, conformação perineal alterada e/ou idade avançada, características que representam os principais fatores de risco para a doença ${ }^{(5,7)}$.

Nos cinco casos positivos do Experimento 2, a presença de leveduras foi diagnosticada nas lâminas citológicas endometriais (Figura 4A) e pela observação do crescimento fúngico de 24 a 48 horas após a semeadura no sistema Dermatobac ${ }^{\circledR}$, padrão de crescimento semelhante ao observado para cepas ATCC no Experimento 1. Dessa forma, a sensibilidade do laminocultivo Dermatobac ${ }^{\circledR}$ foi de $100 \%$, sendo efetivo para a identificação de todos os casos positivos da doença. Das cinco amostras positivas na citologia endometrial e no sistema Dermatobac $\AA$, o teste comprobatório de cultivo revelou que quatro desenvolveram hifas hialinas e ramificadas, sugestivas de leveduras do gênero Candida spp, e uma foi identificada como sendo Aspergyllus spp. Dentre as quatro cepas confirmadas como Candida, duas desenvolveram clamidósporos no teste do tubo germinativo, confirmando o diagnóstico do isolado de campo como Candida albicans ${ }^{(23)}$.

Os agentes patogênicos identificados nas amostras positivas encontravam-se em conformidade com os achados reportados em estudos anteriores, que apontaram Cândida spp e Aspergyllus spp como os principais agentes etiológicos dos quadros de endometrite fúngica em equinos ${ }^{(6,8)}$.

Embora o laminocultivo Dermatobac $₫$ tenha se mostrado sensível para o diagnóstico dos casos positivos de endometrite fúngica, cinco éguas apresentaram resultados negativos na citologia endometrial e positivos no sistema cultivo, sendo considerados como casos falso-positivos (FPs) e determinando a especificidade de $85 \%$. No entanto, em todos os casos FPs foi observado o crescimento de bolores ambientais, caracterizados por colônias filamentosas, algodonosas verde escuro a bege claro, padrão de crescimento idêntico ao observado para as cepas ATCC de Penicillium spp e Cladosporium spp no Experimento 1 (Figuras 4B e 4C).

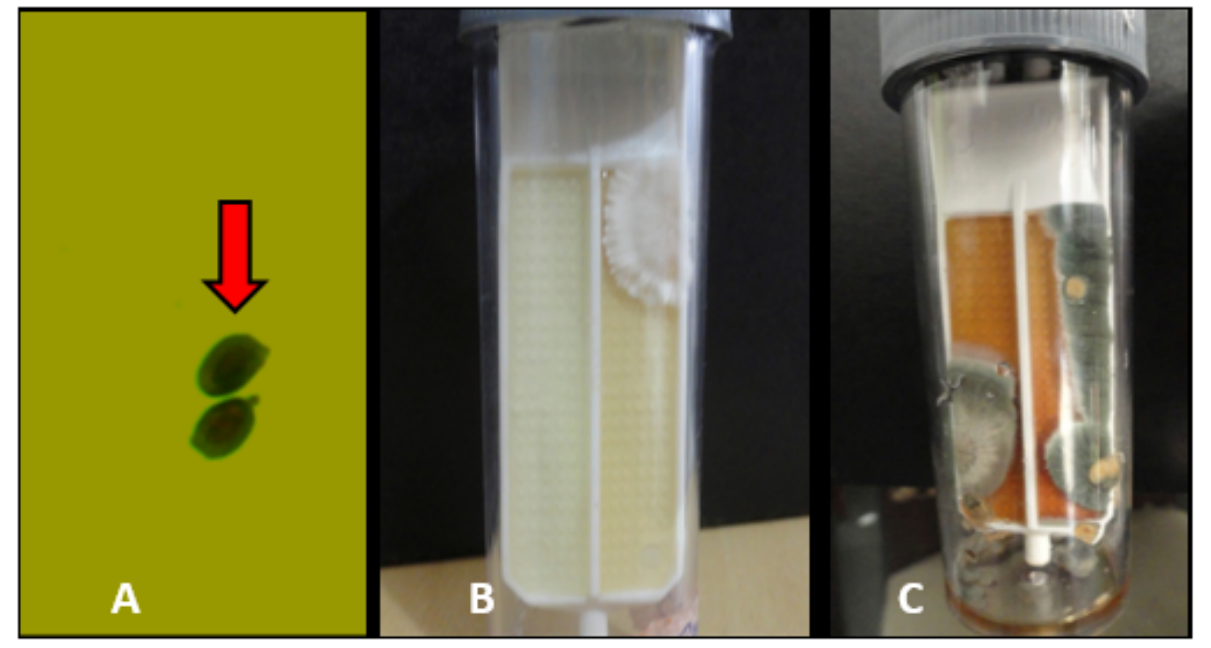

Figura 4: Presença de leveduras (seta) em lâmina citológica endometrial (aumento de $1000 \mathrm{X}$ em objetiva de imersão) de égua de 14 anos de idade e histórico de infertilidade nas estações de monta 2012 e 2013 (A). Bolores que cresceram no sistema Dermatobac® devido à contaminação ambiental durante a colheita de material endometrial (Experimento 2), sugestivos dos gêneros Penicillium spp (B) e Cladosporium spp (C), respectivamente. 
O crescimento desses bolores contaminantes pode ser justificado pela dificuldade de manutenção da assepsia em condições de campo. Embora em estudos anteriores seja ressaltado que o risco de contaminação dificulte a utilização da cultura microbiológica como método diagnostico para a endometrite ${ }^{(16,17)}$, no presente estudo foi observado que o aspecto macroscópico e a taxa de crescimento dos contaminantes foram diferentes do padrão observado para os fungos patogênicos. Em todos os casos FPs, o início da observação macroscópica foi possível somente a partir de seis dias após a semeadura no sistema Dermatobac $\AA$, diferindo do padrão de crescimento apresentado pelas cepas padrão de Cândida spp e Aspergyllus spp (Experimento 1) e dos isolados desses mesmos fungos a partir das amostras de campo (Experimento 2; $\mathrm{P}<0,05$ ). Dessa forma, mesmo com o crescimento inespecífico de fungos ambientais, a sensibilidade e especificidade do Dermatobac ${ }^{\circledR}$ não foram comprometidas, mostrando-se um método efetivo para o diagnóstico da endometrite causada por fungos.

$\mathrm{Na}$ comparação dos métodos de citologia endometrial para pesquisa direta de fungos e cultivo em sistema Dermatobac ${ }^{\circledR}$ foi obtido um valor de Kappa de $64 \%$, resultado que indica uma boa concordância entre o método citológico e o resultado do cultivo $(\mathrm{P}<0,05)$. Dessa forma, mesmo na impossibilidade do diagnóstico citológico, a cultura em Dermatobac ${ }^{\circledR}$ pode ser utilizada para o diagnóstico conclusivo de endometrite fúngica em equinos.

De acordo com Daef et al. ${ }^{(28)}$, a rápida identificação de muitas espécies de fungos é dificultada em vários países pela falta de treinamento dos profissionais da saúde, além da falta de reagentes e equipamentos específicos para o diagnóstico. Dessa forma, a validação de métodos como o laminocultivo Dermatobac ${ }$, que permite o diagnóstico rápido, conclusivo e de baixo custo, possui alto potencial para implementação em Medicina Veterinária, permitindo a identificação de fungos patogênicos mesmo em condições de campo em 24 a 48 horas após a semeadura.

\section{Conclusões}

A prevalência de endometrite fúngica mostrou-se superior ao reportado em estudos anteriores, resultado que ressalta a importância da doença, sobretudo para éguas consideradas como pertencentes ao grupo de risco. O sistema Dermatobac ${ }^{\circledR}$ mostrou-se eficiente para o diagnóstico macroscópico da endometrite fúngica em equinos, gerando informações visuais a partir de 24 horas de cultivo. O sistema mostrou-se eficiente para a identificação dos fungos Candida spp e Aspergyllus spp, principais agentes etiológicos isolados nos casos de endometrites fúngicas. Podem ocorrer problemas de contaminação das amostras biológicas durante a colheita do material em condições de campo. No entanto, a baixa taxa de crescimento e características macroscópicas dos contaminantes favorece a identificação dos casos falso-positivos, não comprometendo a sensibilidade, especificidade e aplicabilidade do sistema Dermatobac $\mathbb{R}$ para o diagnóstico da endometrite causada por fungos.

\section{Referências}

1. Colbern GT, Voss JL, Squires, EL, Ellis RP, Shideler RK, McChesney AE. Development of a model to study endometritis in mares. Equine Veterinary Science, 1987; 7: 73-76.

2. Troedsson MH. Uterine clearance and resistance to persistent endometritis in the mare. Theriogenology, 1999; 52: 461-471.

3. Troedsson MH. Breeding induced endometritis in mare. Veterinary Clinics of North America Equine Practice, 2006; 22: 705-712.

4. Palm J, Walter I, Kolodziejek J, Nowotny N, Hoppen HO, Aurich C. Embryo transfer induces a subclinical endometritis in recipient mares which can be prevented by treatment with non-steroid anti-inflammatory drugs. Theriogenology, 2008; 70: 1147-1158.

5. Dascanio JJ, Schweizer C, Ley WB. Equine fungal endometritis. Equine Veterinary Education, 2001; 13: 
324-329.

6. Dascanio JJ. Treatment of Fungal Endometritis. In: Current Therapy in Equine Reproduction, Elsevier, 2007, 116-120.

7. Silva ACS, Alvarenga MA. Fungal Endometritis. In: Equine Reproduction 2nd edition, Wiley-Blackwell, 2011, 2643-2650.

8. Scofield DB, Wittenburg LA, Ferris RA, Gustafson DL, McCue PM. Equine Endometrial Tissue Concentration of Fluconazole Following Oral Administration. Journal of Equine Veterinary Science, 2013; 33: 44-50.

9. Stefanetti V, Marenzoni ML, Lepri E, Coletti M, Proietti PC, Agnetti F, Crotti S, Pitzurra L, Del Sero A, Passamonti F. Case of Candida guilliermondii abortion in an Arab mare. Medical Mycology Case Reports, 2014; (4):19-22.

10. Card C. Post-breeding inflammation and endometrial cytology in mares. Theriogenology, 2005; 64:580-8.

11. Aguilar J, Hanks M, Shaw DJ, Else R, Watson E. Importance of using guarded techniques for the preparation of endometrial cytology smears in mares. Theriogenology, 2006; 66:423-30.

12. Nielsen JM. Endometritis in the mare: A diagnostic study comparing cultures from swab and biopsy. Theriogenology, 2005; 64: 510-518.

13. Overbeck W, Witte TS, Heuwieser W. Comparison of three diagnostic methods to identify subclinical endometritis in mares. Theriogenology, 2011; 75: 1311-1318.

14. Cocchia N, Paciello O, Auletta L, Uccello V, Silvestro L, Mallardo K, Paraggio G, Pasolini MP. Comparison of cytobrush, cottonswab, and low-volume uterine flush techniques to evaluate endometrial cytology for diagnosing endometritis in chronically infertile mares. Theriogenology, 2012; 77: 89-98.

15. Walter J, Neuberg KP, Failing K, Wehrend A. Cytological diagnosis of endometritis in the mare: Investigations of sampling techniques and relation to bacteriological results. Animal Reproduction Science, 2012; 132: $178-186$.

16. Woodward EM, Troedsson M H. Equine Breeding-Induced Endometritis: A Review. Journal of Equine Veterinary Science, 2013; 33: 673-682.

17. Liu IKM, Troedsson MHT. The diagnosis and treatment of endometritis in the mare: Yesterday and today. Theriogenology, 2008; 70: 415-420.

18. Le Blanc MM, Magsig J, Stromberg AJ. Use of a low-volume uterine flush for diagnosing endometritis in chronically infertile mares. Theriogenology, 2007; 68:403-12.

19. Chaves LJQ. Dermatomicoses em cães e gatos; Avaliação do diagnostico clínico-laboratorial e dos aspectos epidemiológicos em uma população de portadores de lesões alopécicas circulares. Dissertação de mestrado, Fortaleza/CE, 2007. Acesso: 13/08/2014. Disponível em:http://www.uece.br/ppgcv/dmdocuments/ lucio chaves.pdf

20. Borba LA. Coloração de esporos em pelos na dermatofitose em comparação de técnicas de diagnóstico. Dissertação de mestrado, Curitiba/PR, 2010. Acesso: 13/08/2014. Disponível em: http:// dspace.c3sl.ufpr.br:8080/dspace/bitstream/handle/1884/24295/Coloracao $\% 20$ de $\% 20$ esporos $\% 20$ em\%20pelos $\% 20$ na $\% 20$ dermatofitose $\% 20 \mathrm{e} \% 20$ comparacao $\% 20 \mathrm{de} \% 20$ tecnicas $\% 20 \mathrm{de} \% 20$ diagnostico. pdf;jsessionid=941CF1FD60A84A6C7D866B338C1405F5?sequence $=1$

21. Gajos K, Kozdrowski R, Nowak M, Siemieniuch MJ. Altered secretion of selected arachidonic acid metabolites during subclinical endometritis relative to estrous cycle stage and grade of fibrosis in mares. Theriogenology, 2015; 84: 457-466.

22. Defontis M, Vaillancourt D, Grand X. Comparison of three methods of sampling for endometrial cytology in the mare. Tierärztliche Praxis Großtiere, 2011; 33:171-176.

23. Agencia Nacional de Vigilância Sanitária (ANVISA). Detecção e Identificação dos Fungos de Importância Médica, 2004.

24. Dumitru R, Hornby JM, Nickerson KW. Defined Anaerobic Growth Medium for Studying Candida albicans. Basic Biology and Resistance to Eight Antifungal Drugs. Antimicrobial Agents and Chemotherapy, 2004; 48(7): 2350-2354.

25. Alterthum, F.; Trabulsi L. R. Microbiologia. Editora Atheneu, São Paulo, 2008. p256-258. 
26. Ilkit M, Hilmioglu S, Tasbakan M, Aydemir S. Evaluation of Albicans ID2 and Biggy agar for the isolation and direct identification of vaginal yeast isolates. Journal of Medical Microbiology, 2007; 56: 762-765.

27. Nickerson W J. Reduction of inorganic substances by yeasts. I. Extracellular reduction of sulfite by species of Candida. Journal of Infectious Diseases, 1953; 93 (1): 43-56.

28. Daef E, Moharram A, Eldin SS, Elsherbiny N, Mohammed M. Evaluation of chromogenic media and seminested PCR in the identification of Candida species. Brazilian Journal of Microbiology, 2014; 45: 255262. 